NHS Blood and Transplant, National Institute for Health Research Oxford Biomedical Research Centre, University of Oxford, Oxford, UK

Correspondence to: L J Estcourt lise.estcourt@nhsbt.nhs.uk) Cite this as: BMJ 2020;370:m3516 http://dx.doi.org/10.1136/bmi.m3516 Published: 15 September 2020

\section{Convalescent plasma for covid-19}

\author{
Authorisation in the US was premature, and a missed opportunity
}

\author{
Lise J Estcourt, David J Roberts
}

Plasma from people recovering from infection, particularly after severe illness, may contain high levels of polyclonal, pathogen specific antibodies. These antibodies may confer passive immunity to recipients, and in viral diseases are thought to act mainly by neutralising viral particles. ${ }^{1}$ Convalescent plasma, or purified antibodies from the plasma (hyperimmune globulin), was often used in clinical practice before the advent of vaccines, including during the influenza pandemic of $1918 .^{2}$

Hyperimmune globulin is still used for post-exposure prophylaxis against various viral infections, including hepatitis B, varicella zoster, and rabies.

The use of convalescent plasma to treat patients with covid-19 has understandably attracted a lot of attention, but definitive evidence of efficacy has been elusive. Nevertheless, on 23 August the US Food and Drugs Administration authorised its emergency use for hospital patients with covid-19. At the time, only two small underpowered trials had been published. ${ }^{34}$

Until this authorisation the large scale clinical administration of convalescent plasma in the US was regulated under the FDA's expanded access treatment protocol, which required individual patient authorisation and collection of data on clinical outcomes and side effects. Over five months, from 1 April 2020, the protocol served over 2700 hospitals and enrolled over 100 ooo patients. ${ }^{5}$ The initial purpose of the data collection was to establish the safety of convalescent plasma. ${ }^{6}$ However, the data were also analysed for signals of efficacy, despite a lack of control data from patients treated without convalescent plasma. After reviewing these analyses and other experimental and historical data, the FDA judged that convalescent plasma "may be effective" and was therefore eligible for wider use under an emergency use authorisation. ${ }^{7}$ All adults being treated for covid-19 in US hospitals can now be given convalescent plasma.

Although the FDA still states that "Adequate and well-controlled randomized trials remain necessary for a definitive demonstration of CCP [convalescent plasma] efficacy and to determine the optimal product attributes and appropriate patient populations for its use," doctors and hospitals are no longer obliged to report data on clinical outcomes. The only requirement is to report deaths related to transfusion. ${ }^{8}$ Experts argue that the emergency use authorisation will make it more difficult to recruit participants for randomised trials of convalescent plasma in the US.

What other evidence underpinned the FDA's controversial decision? The most recent version of the Cochrane living systematic review on convalescent plasma ${ }^{9}$ was available, along with more recent randomised and non-randomised studies. ${ }^{410-15}$ However, the only two randomised trials (189 participants in total) ${ }^{34}$ could not be combined in meta-analyses because they used different times for assessing mortality and different rating scales for clinical outcomes. Meta-analysis of individual patient data would overcome these problems and should be done. Even if these small trials could be combined, the analyses would not be powerful enough to detect a significant difference in all-cause mortality, arguably the most important outcome, and a conclusive meta-analysis may require inclusion of data from the many randomised trials currently in progress.

For safety data, the FDA relied mainly on the expanded access programme, ${ }^{6}$ which collected data on serious adverse events among the 20 ooo patients treated with convalescent plasma. The incidence of adverse events related to transfusion (transfusion associated circulatory overload, transfusion related acute lung injury, and severe allergic reactions) in the first four hours after transfusion was low $(<1 \%)$, and the immediate risks associated with convalescent plasma transfusions are widely agreed to be no greater than those associated with transfusions of standard plasma. Crucially, there has been no evidence so far of antibody mediated enhancement of disease in covid-19 patients given convalescent plasma despite suggestions that this might be a possibility in the presence of reactive but non-neutralisng antibodies against SARS-CoV-2. ${ }^{16}$, 17

The US National Institutes of Health and the FDA are clear that efficacy of convalescent plasma for covid-19 is not yet established and that every effort should be made to complete further randomised trials. ${ }^{7}$ At least 73 trials are already underway worldwide. No country, including the US, has licensed convalescent plasma as a treatment for covid-19, although other countries have granted approval for use on an individual patient basis.

The lack of randomised trial evidence from the US reflects a missed opportunity. If large simple trials had started in the US at the same time as the extended access programme, we would already know whether convalescent plasma is effective and safe. The UK has shown that large simple trials, such as the RECOVERY trial, are feasible and can provide answers to important therapeutic questions during a pandemic. ${ }^{18}$ The RECOVERY and REMAP-CAP trials are both evaluating convalescent plasma in patients with covid-19 being treated at 190 hospitals in the UK. Results are expected by the end of 2020, although completion ultimately depends on rates of admission for covid-19 in participating hospitals. 
What is certain is that high quality evidence from randomised controlled trials is needed to drive the development of large-scale plasma collection internationally, to inform reliable guidelines for clinical use, and to provide the maximum benefit to patients.

Competing interests: The BM/ has judged that there are no disqualifying financial ties to commercial companies. The authors declare the following other interests: LE and DJR are clinical workstream and medical leads for the convalescent plasma programme at NHS Blood and Transplant and co-chief principal investigators and joint principal investigators for the convalescent plasma arms of the REMAP-CAP and RECOVERY trials. The BMJ policy on financial interests is here: https://www.bmj.com/sites/default/files/attachments/resources/2016/03/16-current-bmj-educationcoi-form.pdf.

Provenance and peer review: Commissioned; not externally peer reviewed.

1 Casadevall A, Pirofski L-A. The convalescent sera option for containing COVID-19. J Clin Invest 2020;130:1545-8. doi: 10.1172/JCl138003 pmid: 32167489

2 Mair-Jenkins J, Saavedra-Campos M, Baillie JK, etalConvalescent Plasma Study Group. The effectiveness of convalescent plasma and hyperimmune immunoglobulin for the treatment of severe acute respiratory infections of viral etiology: a systematic review and exploratory meta-analysis. J Infect Dis 2015;211:80-90. doi: 10.1093/infdis/jiu396 pmid: 25030060

3 Li L, Zhang W, Hu Y, etal. Effect of convalescent plasma therapy on time to clinical improvement in patients with severe and life-threatening covid-19: a randomized clinical trial. JAMA2020 [Epub ahead of print]. doi: 10.1001/jama.2020.10044 pmid: 32492084

4 Gharbharan A. Convalescent plasma for covid-19. A randomized clinical trial. medRxiv 2020:2020.07.01.20139857. [Preprint.] doi: 10.1101/2020.07.01.20139857v1

5 Mayo Clinic. US covid plasma, 6 Sep 2020 https:/www.uscovidplasma.org/

6 Joyner MJ, Bruno KA, Klassen SA, etal. Safety update: covid-19 convalescent plasma in 20,000 hospitalized patients. Mayo Clin Proc 2020;95:1888-97. doi: 10.1016/.jmayocp.2020.06.028 pmid: 32861333

7 FDA. Clinical memorandum: covid-19 convalescent plasma. 2020. https://www.fda.gov/media/141480/download

8 FDA. Notification process for transfusion related fatalities and donation related deaths. 2020 https://www.fda.gov/vaccines-blood-biologics/report-problem-center-biologics-evaluation-research/transfusiondonation-fatalities

9 Piechotta V, Chai KL, Valk SJ, etal. Convalescent plasma or hyperimmune immunoglobulin for people with COVID-19: a living systematic review. Cochrane Database Syst Rev 2020;7: doi: 10.1002/14651858.cd013600.pub2. pmid: 32648959

10 Rasheed AM, Fatak DF, Hashim HA, et al. The therapeutic effectiveness of convalescent plasma therapy on treating COVID-19 patients residing in respiratory care units in Baghdad. medRxiv 2020:2020.06.24.20121905v2. [Preprint.] doi: 10.1101/2020.06.24.20121905v2

11 Abolghasemi H, Eshghi P, Cheraghali AM, etal. Clinical efficacy of convalescent plasma for treatment of COVID-19 infections: results of a multicenter clinical study. Transfus Apher Sci2020: [Epub ahead of print.]. doi: 10.1016/j.transci.2020.102875 pmid: 32694043

12 Hegerova L, Gooley TA, Sweerus KA, etal. Use of convalescent plasma in hospitalized patients with COVID-19: case series. Blood 2020;136:759-62. doi: 10.1182/blood.2020006964 pmid: 32559767

13 Martinez-Resendez MF, Castilleja-Leal F, Torres-Quintanilla A, et al. Initial experience in Mexico with convalescent plasma in COVID-19 patients with severe respiratory failure, a retrospective case series. medRxiv2020:2020.07.14.20144469. [Preprint.] doi: 10.1101/2020.07.14.201444469

14 Hartman W, Hess AS, Connor JP. Hospitalized COVID-19 patients treated with convalescent plasma in a mid-size city in the midwest. medRxiv2020:2020.06.19.20135830. [Preprint.] doi: 10.1101/2020.06.19.20135830

15 Madariaga MLL, Guthmiller J, Schrantz S, et al. Clinical predictors of donor antibody titer and correlation with recipient antibody response in a COVID-19 convalescent plasma clinical trial. medRxiv 2020. [Preprint.] doi: 10.1101/2020.06.21.20132944

16 Sewell HF, Agius RM, Kendrick D, Stewart M. Vaccines, convalescent plasma, and monoclonal antibodies for covid-19. BMJ2020;370:m2722. doi: 10.1136/bmj.m2722 pmid: 32646867

17 Arvin AM, Fink K, Schmid MA, etal. A perspective on potential antibody-dependent enhancement of SARS-CoV-2. Nature 2020;584:353-63. doi: 10.1038/s41586-020-2538-8 pmid: 32659783

18 Horby P, Lim WS, Emberson JR, etalRECOVERY Collaborative Group. Dexamethasone in hospitalized patients with Covid-19 - Preliminary Report. N Engl / Med 2020. [Epub ahead of print.] doi: 10.1056/NEJMoa2021436. pmid: 32678530

This article is made freely available for use in accordance with BMJ's website terms and conditions for the duration of the covid-19 pandemic or until otherwise determined by BMJ. You may use, download and print the article for any lawful, non-commercial purpose (including text and data mining) provided that all copyright notices and trade marks are retained. 